\title{
The effects of atropine on food-reinforced vs water-reinforced VI responding
}

GARTH HINES, WILLIAM T, MILLER, and ANDREW E. LEE, University of Montana, Missoula, Mont. 59801

Both atropine sulfate and atropine methyl nitrate $(2 \mathrm{mg} / \mathrm{kg})$ were found to suppress VI responding for food reinforcement, while neither had a significant effect on responding for water reinforcement. It was suggested that suppression of thirst-related behavior by anticholinergic substances is a dose-related function of both the central and the peripheral consequences of cholinergic attenuation.

Grossman (1960) has suggested that cholinergic activity, in a circumscribed perifornical area at the same rostrocaudal coordinate as the ventromedial nucleus, selectively activates drinking behavior. While the structures involved in water in take have been extended by research involving central application of cholinergic and anticholinergic substances (Fisher \& Coury, 1962; Levitt \& Fisher, 1966), the specificity of the relationship between cholinergic activity and drinking behavior has been maintained.

Peripherally applied anticholinergic substances have been shown to suppress food in take as well (Stein, 1963; Whitehouse et al, 1964). This effect is thought to be due to the peripheral consequences of cholinergic attenuation rather than to central actions. The quaternary analogs of atropine and scopolamine, which penetrate the blood-brain barrier only with difficulty, are somewhat more potent than atropine or scopolamine in suppressing food intake (Stein, 1963). Further, Artane, an anticholinergic which causes only mild dryness of the throat peripherally, has been shown to have no effect on the consumption of food reinforcement (Keehn \& Nagai, 1969).

The peripheral application of atropine has also been shown to suppress water intake (Grossman, 1962), as well as to affect water-reinforced responding on multiple schedules (Herrnstein, 1958; Boren \& Navarro, 1959; Willis \& Windland, 1963). These effects on thirst-related behavior may, however, be dose-dependent (Boren \& Navarro, 1959; Stein, 1963).

The present experiment was designed to test the effects of a comparatively low dose $(2 \mathrm{mg} / \mathrm{kg})$ of atropine sulfate and atropine methyl nitrate on VI responding as a function of the type of reinforcement employed. The effects of repeated administration on response output was also investigated.

\section{SUBJECTS}

Forty-two male Long-Evans hooded rats, $90-120$ days of age at the beginning of the experiment, were randomly divided into six equal groups. The $\mathrm{Ss}$ were maintained at $80 \%$ of their estimated growth curve-three groups by controlled feeding at the end of each day's run, and three by timed access to water at the end of each day's run. All Ss were housed in individual home cages.

$$
\text { APPARATUS }
$$

Subjects were tested in two Lehigh Valley rat chambers, housed in sound-insulated, ventilated chests. The left bar in each chamber was removed, and its opening was covered with a metal plate set flush with the wall. Water reinforcements were delivered by a Lehigh Valley Model 1351 liquid dipper, and food reinforcements by a Scientific Prototype Model D700 pellet dispenser. Electronic programming and recording equipment was activated by a force of $12 \mathrm{~g}$ on each bar.

\section{PROCEDURE}

All Ss were trained to barpress on a VI 30-sec schedule for either food (94-mg Noyes pellet) or water $(.04 \mathrm{cc}, 4-\mathrm{sec}$ presentation) reinforcement. They were run for one 16-min period per day, to a criterion of either 5 consecutive days where the daily total responses fell within $\pm 10 \%$ of the mean response total for the previous 5 days, or for 60 days, whichever came first. For 10 days following criterion, $S s$ received i.p. injections of either $1 \mathrm{cc} / \mathrm{kg}$ isotonic saline (Groups F/S and W/S, i.e., food or water reinforcement with saline), $2 \mathrm{mg} / \mathrm{cc} / \mathrm{kg}$ atropine sulfate in isotonic saline (Groups $\mathrm{F} / \mathrm{AS}$ and $\mathrm{W} / \mathrm{AS}$ ), or $2 \mathrm{mg} / \mathrm{cc} / \mathrm{kg}$ atropine methyl nitrate in isotonic saline (Groups F/AMN and W/AMN). Injections were given 30 min prior to the day's run.

$$
\text { RESULTS }
$$

The data from the first of the $10 \mathrm{drug}$ days was judged to be confounded by reaction to the injection procedure itself, and was discarded. The remaining 9 days were grouped into blocks of 3 , and a suppression ratio (total responses in each 3-day block divided by the total responses for the last 3 criterion days) was computed for each S. A 2 by 3 by 3 (reinforcement by drug by trial block) factorial analysis was used, with repeated measures on the first factor. The reinforcement, drug, drug by reinforcement, and drug by reinforcement by trial block factors were all significant $(\mathrm{p}<.01)$, as was the reinforcement by trial block interaction $(p<.05)$. However, since the three-way interaction and the reinforcement by trial block interaction accounted for so small a proportion of the total variance $\left(\omega^{2}=.001\right.$ and .0005 , respectively), they will not be discussed in detail here.

The mean suppression ratio for each group is shown in Fig. 1. Groups F/AS and F/AMN both showed extensive response suppression, while there was a nonsignificant tendency for Groups W/AS and W/AMN to respond at a slightly higher rate than Group W/S. The food-reinforced Ss tended to decrease their response output over trials, while the water-reinforced Ss tended to increase their response output. Individually, neither trend was significant, although the interaction was significant at $\mathrm{p}<.01$. The drug by trial block interaction was not significant ( $p>.10)$, nor was the trial block factor $(p>.05)$.

\section{DISCUSSION}

The present results support previous research showing that both atropine sulfate and atropine methyl nitrate suppress food-reinforced responding. That this suppression is due to the peripheral action of the drug has been suggested previously (Stein, 1963), and receives some further support in this study from the tendency for the food-reinforced Ss to decrease their response output as a function of the number of injection days. Such a response decrease might be expected to occur if the peripheral consequences of cholinergic attenuation result in a decrease in the incentive value of the reinforcement pellets. This

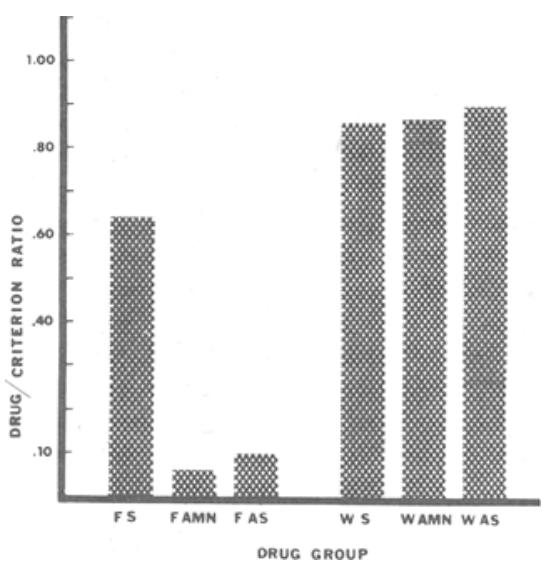

Fig. 1. Mean suppression ratio as a function of drug group. 
interpretation is supported by the tendency of several of the $S s$ in both Group F/AS and Group F/AMN to leave up to $50 \%$ of the pellets they received uneaten.

Suppression of water-reinforced responding was not found for either Groups W/AS or W/AMN, a result which is in accord with previous work (Stein. 1963) showing no significant suppression of water intake with a dose of $2.5 \mathrm{mg} / \mathrm{kg}$ atropine, although there was a significant suppression with a dose of $5 \mathrm{mg} / \mathrm{kg}$. Thus, the effects of atropine on thirst-related behavior would appear to be dose-dependent. It is quite likely that the degree of suppression is not a simple function of the degree of cholinergic attenuation in the central nervous system, but rather a complex function of that attenuation in relation to the amount of anticholinergically induced peripheral feedback. At low dose levels, the peripheral feedback should induce sufficient activity in the central structures involved in thirst-related behavior so as to counteract the partial inhibition of those structures. As the dose level increases, the degree of central attenuation should become great enough so that the peripheral feedback should have minimal effect, and thirst-related behavior should show maximal suppression.

\section{REFERENCES}

BOREN, J. J., \& NAVARRO, A.P. The action of atropine, benactyzine, and scopolamine upon fixed-interval and fixed-ratio behavior. Joumal of the Experimental Anatysis of Behavior, 1959 2, 107-115.

FISHER, A. E., \& COURY, J. N. Cholinergic tracing of a central neural circuit underlying the thirst drive. Science, 1962, 138,691-693.

GROSSMAN, S. P. Eating and drinking elicited by direct adrenergic or cholinergic stimulation of hypothalamus. Science, 1960, 132, 301-302.

GROSSMAN, S. P. Effects of adrenergic and cholinergic blocking agents on hypothalamic mechanisms. American Journal of Physiology, $1962,202,1230-1236$

HERRNSTEIN, R. J. Effects of scopolamine on a multiple schedule. Journal of the Experimental Analy sis of Behavior, 1958, 1, 351-358.

KEEHN, J. D., \& NAGAI, M. Attenuation of schedule-induced polydipsia by trihexyphenidyl. Psychonomic Science, 1969, 15, 61-62.

LEVITT, R. A., \& FISHER, A. E. Anticholingergic blockade of centrally induced thirst. Science, $1966,154,520-522$.

STEIN, L. Anticholinergic drugs and the central control of thirst. Science, 1963, 139, 46-48.

WHITEHOUSE, J. M., LLOYD, A. J., \& FIFER, A. Comparative effects of atropine and methylatropine on maze acquisition and eating. Journal of Comparative \& Physiological Psychology, 1964, 58, 475-476.

WILLIS, R. D., \& WINDLAND, L. M. Effects of repeated administrations of atropine on two multiple schedules. Psychonomic Science, $1968,13,139-140$. established phenomenon with single altennating partial reinforement (Capaldi. 1967). Within the area of partially delayed reward, Cogan and Capaldi (1961) reported a failure to find pattern running whell a $20-\sec$ delay occurred in the goal box. Burt \& Wike (1963) replicated the Cogan and Capaldi findings but reported pattern running when delays were extended to 60 and $100 \mathrm{sec}$.

The purposes of the present study were: (1) to determine if pattern running would occur at 20 -sec delays if the delay occurred in a separate distinctive delay chamber, (2) to assess the effects of D-I transitions at long and short intertrial intervals, and (3) to determine the effects of sequence of confinement in extinction.

\section{METHOD}

Forty naive female albino rats, approximately 120 days old, were maintained on a 23-h food-deprivation schedule. Ss were adjusted to the deprivation schedule, handled, and tamed during the first 10 days of the experiment.

The apparatus, a 5-ft 3-in. L-shaped nunway was painted flat black and covered with a hardware cloth top, with the exception of an unpainted, Plexiglas-covered delay chamber that separated the run and goal sections. Response times were recorded in $.01-\mathrm{sec}$ units for three 1-ft sections of the runway by means of a system of photo relays and Hunter Klockounters.

Following 4 days of runway exploration, all Ss were given two trials without delay to a standard reward of two $.097 \mathrm{~g}$ Noyes pellets. After the above pretraining, $20 \mathrm{Ss}$ were randomly assigned to either D-I or I-D acquisition sequences and given two trials/day for 16 days. Following acquisition, each original group was divided into four equal subgroups and given 8 days of extinction training at two trials a day. During extinction, Ss were confined in the delay chamber (prior to entering the empty goal box), according to one of the following daily sequences: D-D, D-I, I-D, or I-I. The design then was a 2 by 4 factorial with two levels of trial sequence in acquisition and four levels of trial sequence in extinction. Delay and goal box confinement times were $20 \mathrm{sec}$ during both acquisition and extinction. Trials were rotated among $\mathrm{Ss}$ in squads of eight with one $S$ from each cell represented. The squads were run in a random order each day and fed daily at least 20 min after the completion of training. The intertrial interval (ITI) averaged approximately 7 min during acquisition but gradually increased to approximately $20 \mathrm{~min}$ during extinction.

\section{RESULTS}

Response times for the third measure (entering the delay chamber) were 